\title{
أثر أوامر الدّفاع على الصّلاحية التشريعيّة (دراسة تحليليّة نقديّة في ضوء الدستور الأردنيّ)
}

\author{
نهلا عبد القادر المومنهي \\ دكتوراه في القانون الدوليّ العام \\ ميسّرة أعمال مفوّضية الحماية \\ المركز الوطنيّ لحقوق الإنسان- الأردن \\ nahla400086@yahoo.com
}

\author{
سيف زياد الجنيدي \\ دكتوراه في القانون الدستوريّ والإداريّ \\ رئيس وحدة التشريعات الوطنيّة \\ المركز الوطنيّ لحقوق الإنسان- الأردن \\ aljunidisaif@hotmail.com
}




\section{أثر أوامر الدّفاع على الصّّلاحية التشريعيّة \\ (دراسـة تحليليّة نقديّة في ضيوء الدستور الأردنيّ) \\ سيف زيـاد الجنيدي}

دكتوراه في القانون الدستوريّ والإداريّ- رئيس وحدة التشريعات الوطنيّة- المركز الوطنيّ لحقوق الإنسان- الأردن

aljunidisaif@hotmail.com

$$
\text { نهالا عبد القادر المومني }
$$

دكتوراه في القانون الدوليّ العام- ميسّرة أعمال مفوّضية الحماية- المركز الوطنيّ لحقوق الإنسان- الأردن

nahla400086@yahoo.com

DOI: https://doi.org/10.31559/LCJS2021.2.1.3 2021/4/22 2021/2/14 مراجعة البحث: 2021/4/12 قبول البحث البحث: 2012

ناقشت هذه الدّراسـة بعنوانها الافتراضيّ جدليّة واقعيّة حول أثر أوامر الدّفاع على الصّّلاحية التشريعيّة. تركّزت منهجية الدّراسـة حول

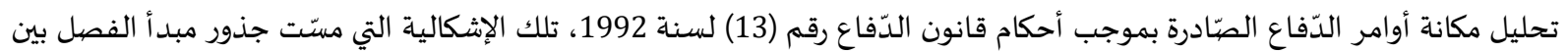

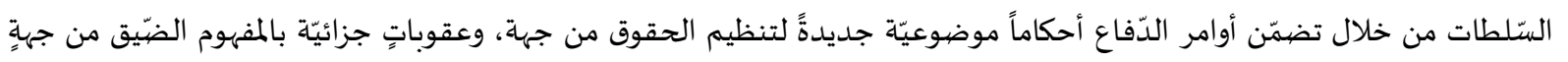
أخرى.

افتراضية عنوان الدّراسة تكمن في نتائجها التي خرجت بنتيجةٍ قانونيّةٍ تتلخّص بالاستحالة القانونيّة لوجود أثرٍ لقانون الدّفاع على

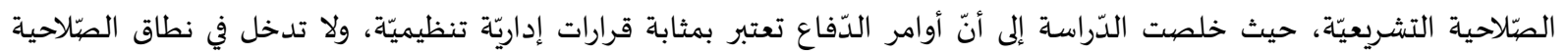

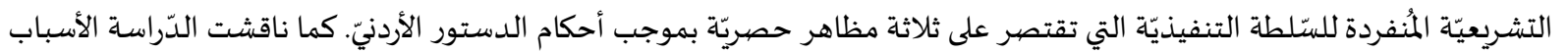

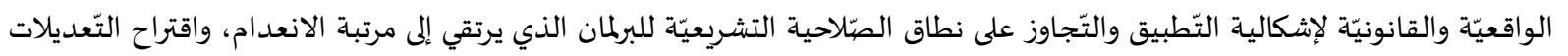
اللازمة لتجسيد مقتضيات مبدأ الفصل بين السّلطات في ممارسة الواجب التّشريعيّ. الكلمات المفتاحيّة: قانون الدّفاع؛ أوامر الدّفاع؛ الملكية الدستوريّة؛ الشرعية الدستوريّة؛ مبدأ الفصل بين السّلطات.

استجابةً للظروف الواقعيّة التي فرضتها جائحة كورونا، صددرت الإرداة الملكيّة في منتصف آذار 2020 بالمُوافقة على قرار مجلس الوزراء بتراء بتطبيق

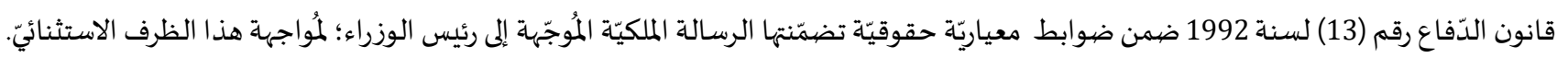

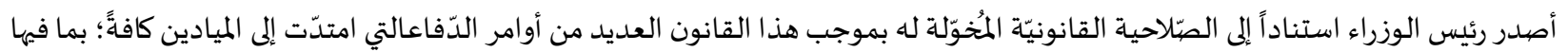

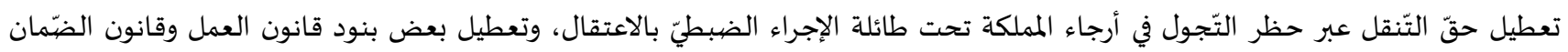

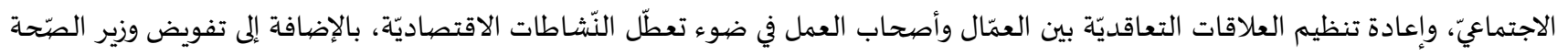

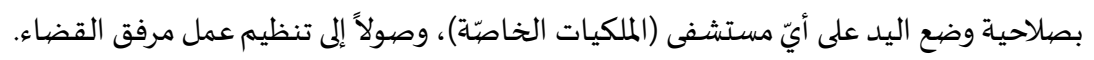


إبان إصدار أوامر الدّفاع المتلاحقة، باعتبارها التّجربة الأولى لتطبيق أحكام هذا القانون منذ سنّه، ثار جدالُّ قانونيّ حول التّكييف القانونيّ

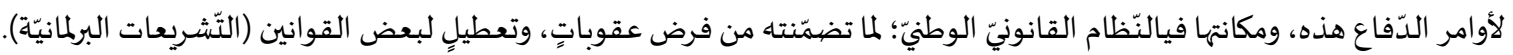

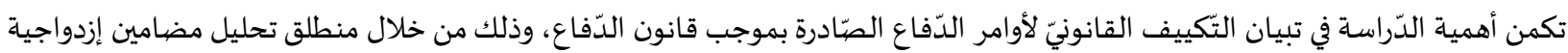

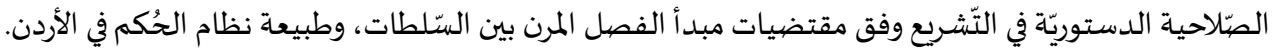

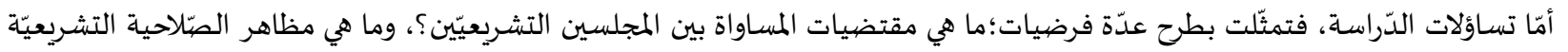

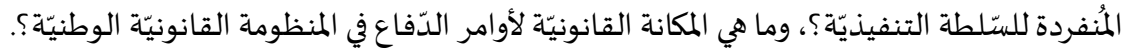

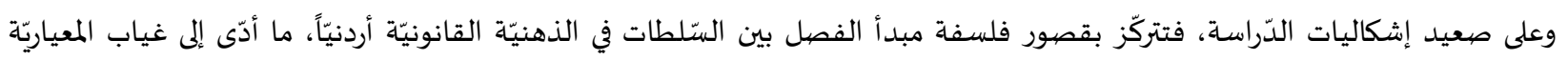
الحقوقيّة في تطبيق أوامر الدّفاع. وعن منهج الدّراسة، فيتمثّل في المنهج التحليليّ النقديّ لمراحل العملية التشريعيّة في النّظام الدستوريّ الأردنيّ، ودراسة حالات تطبيقيّة لدور الملك في معياريّة التُشريع.

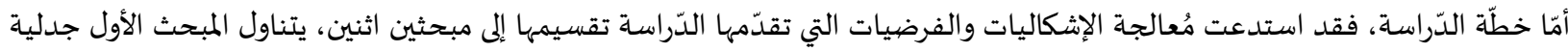

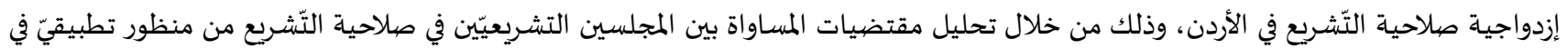

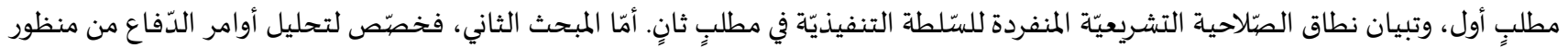

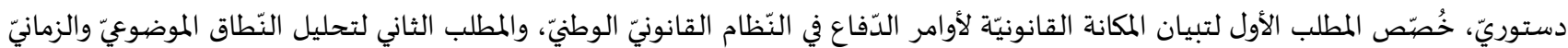
لأوامر الدّفاع.

\section{المبحث الأول: جدلية إزدواجية صلاحية التّشريع في الأردن}

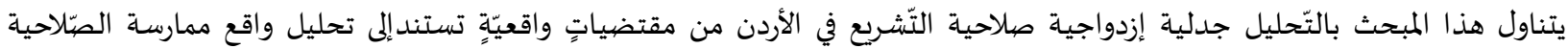

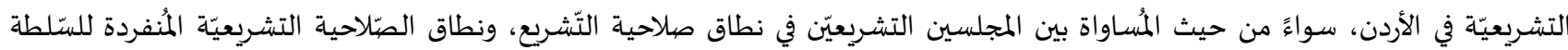

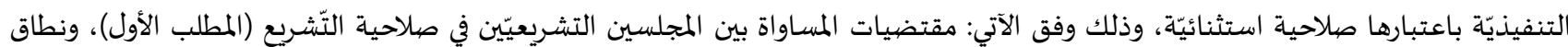

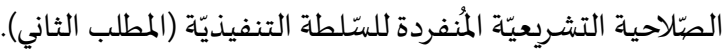

المطلب الأول: مقتضيات المساواة بين المجلسين التشريعيّين في صلاحية التّشريع

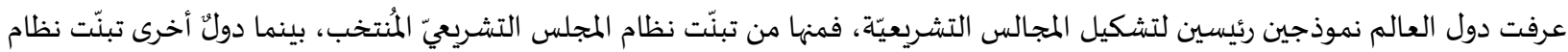

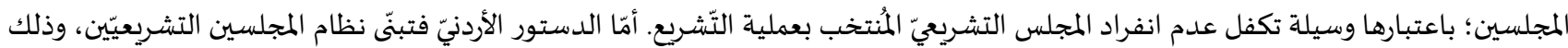

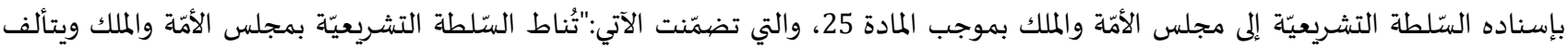
مجلس الأمّة من مجلسيّ الأعيان والنّواب".

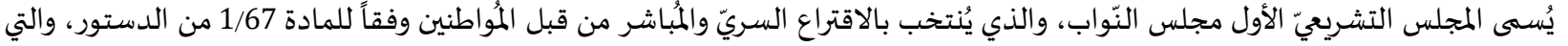

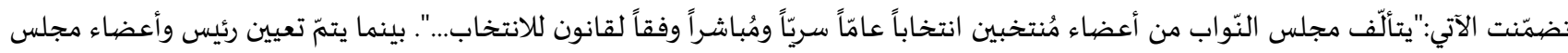

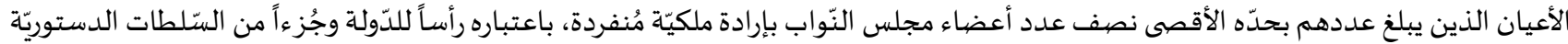

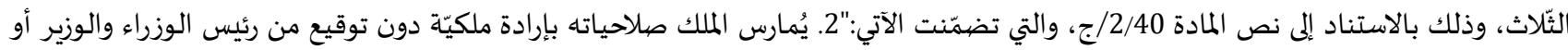

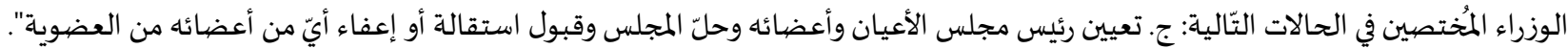

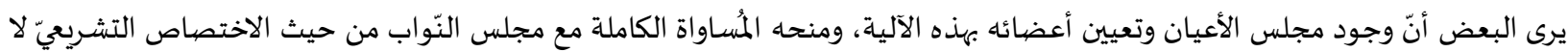

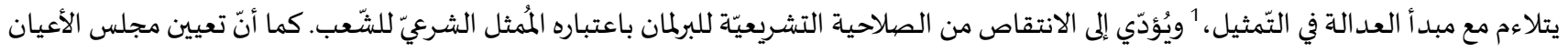

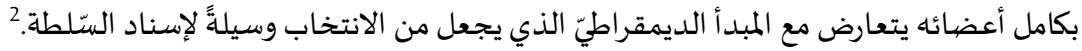

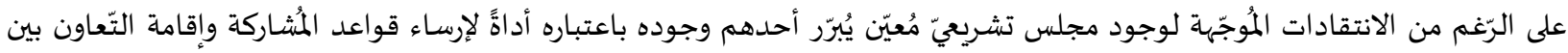

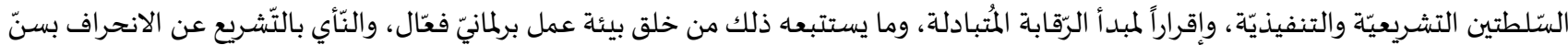

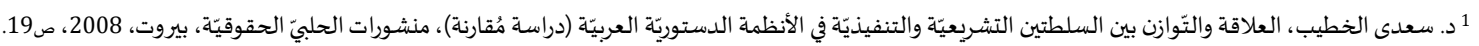

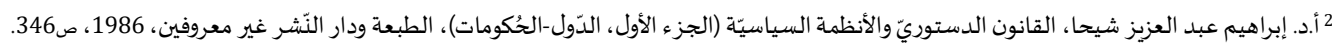


قواعد قانونيّة بهدف مُراعاة مصالح خاصيّة لبعض الأفراد أو المُؤسسات. علاوةً على أنّ منح مجلس الأعيان الاختصاص التشريعيّ يُؤدي إلى عدم

استبداد مجلس واحد في العملية التشريعيّة. 4

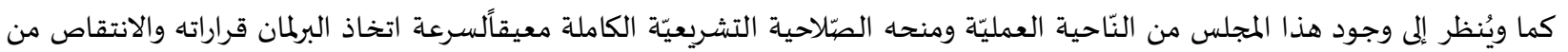

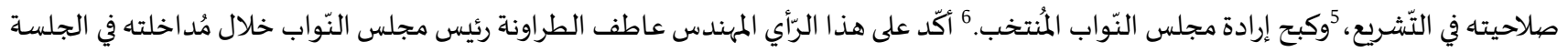

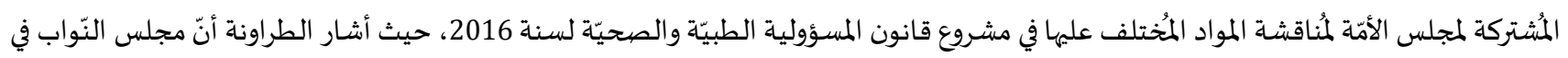

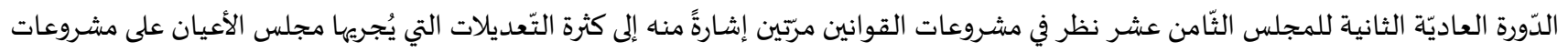

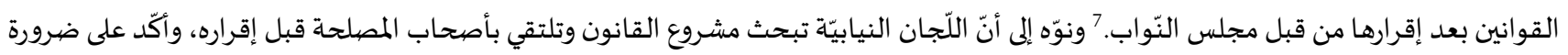

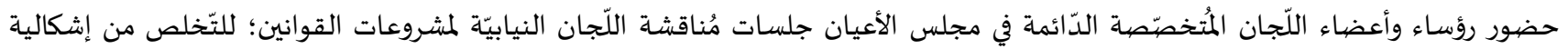
الإعادة والتّعديل من قِبل مجلس وأس الأعيان.

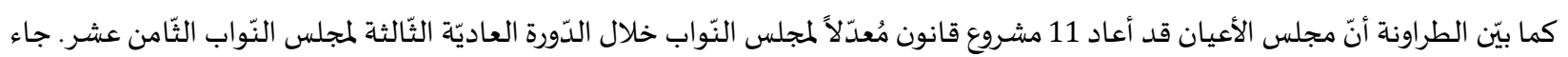

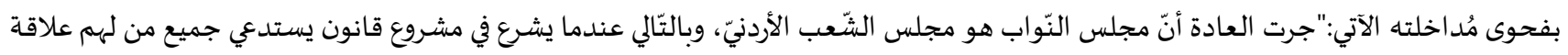

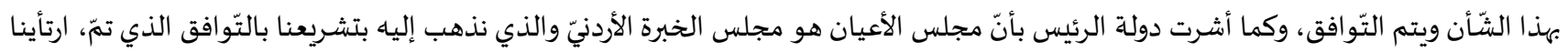

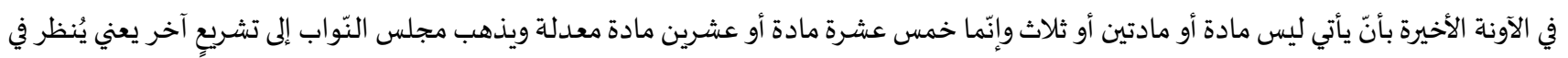

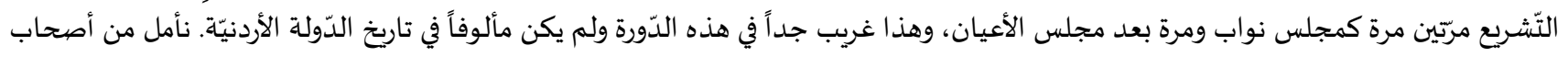

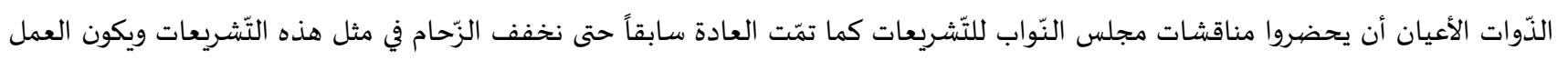
تشاركيّاً ولتحقيق الصيّالح العام". في ضوء تباين الآراء حول شرعية وجود مجلس تشريعيّ مُعيّن من قبل الملك،لا بدّ من الإشارة إلى أنّ طبيعة النّظام الملكيّ في الأردن ومفهوم الملكية

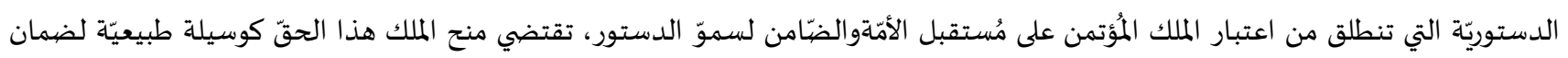

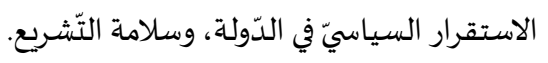

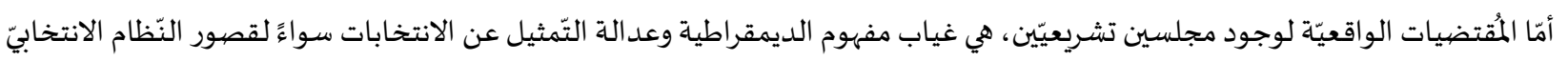

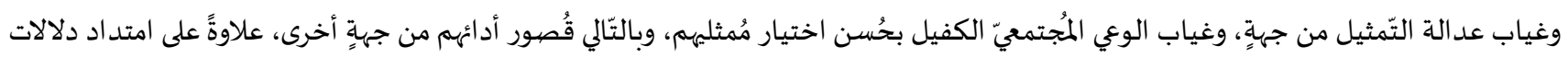

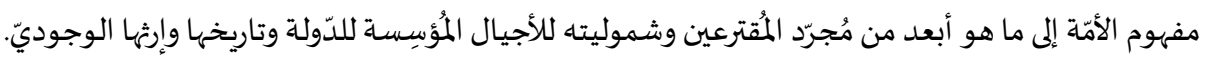

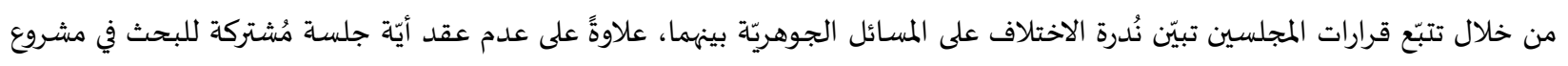

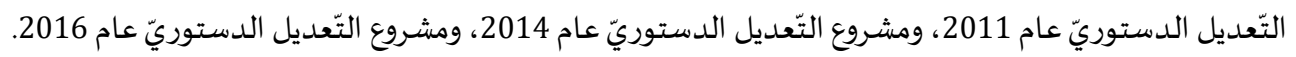

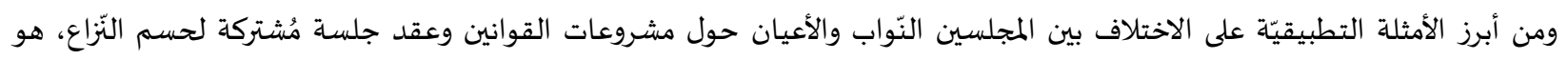

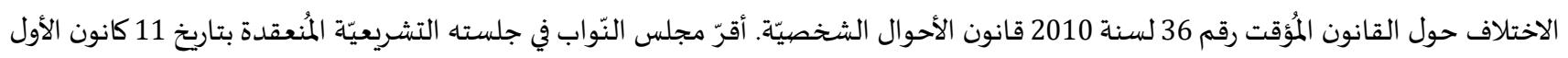

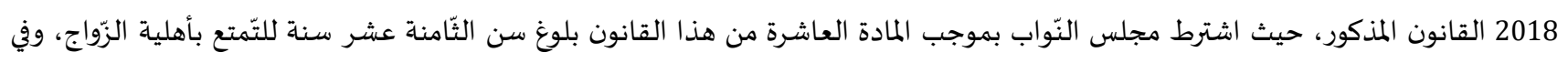

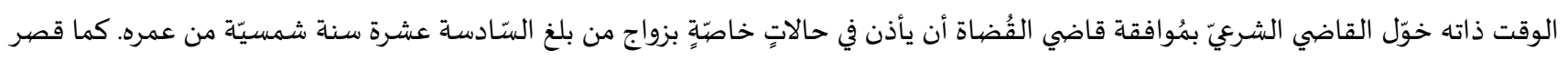

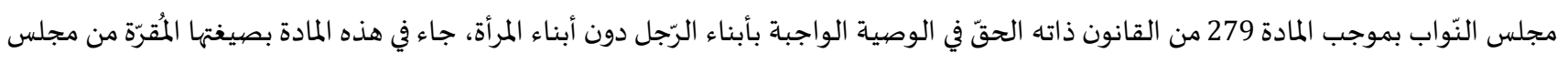

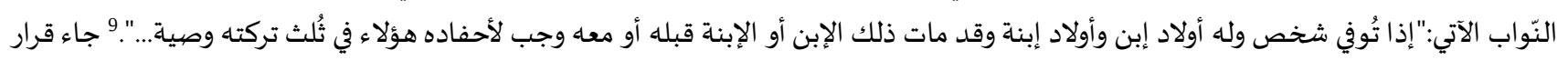

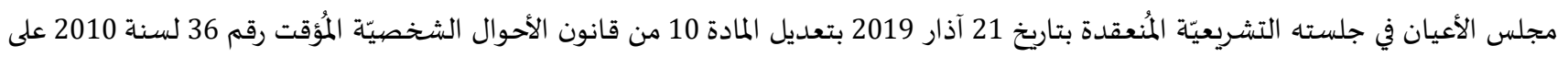

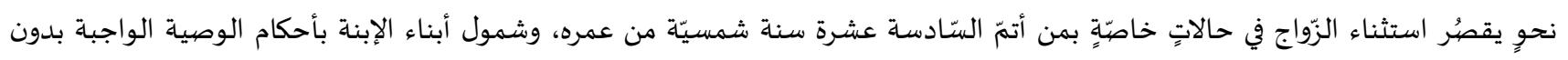

اقتصارها على أبناء الإبن.

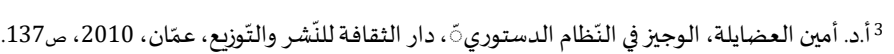

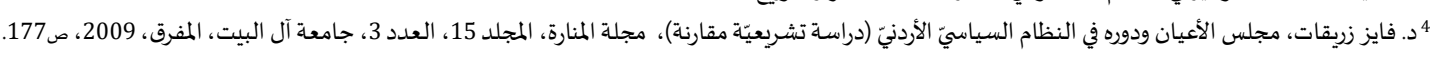

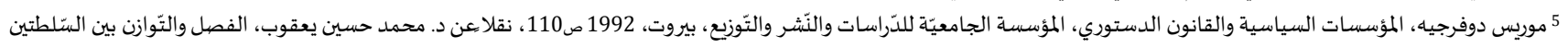

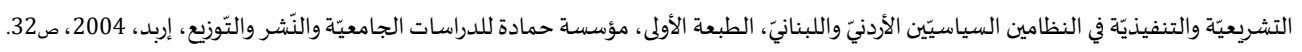

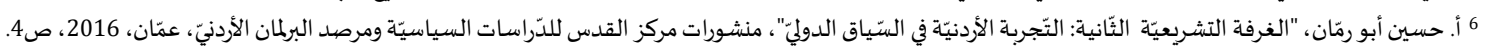

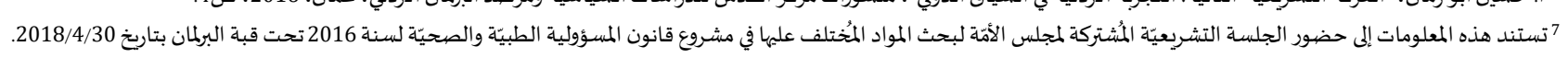
8 المرجع الستّابق ذاته.

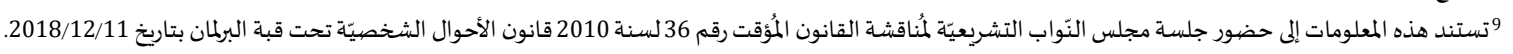

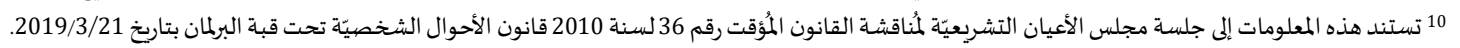




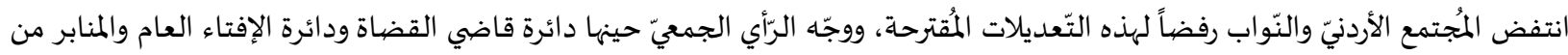

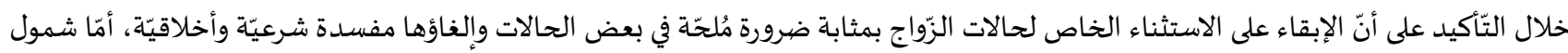

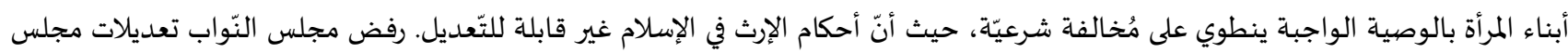

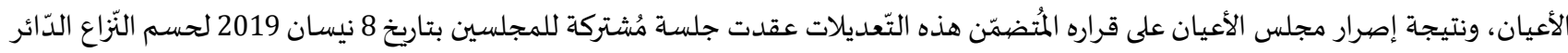

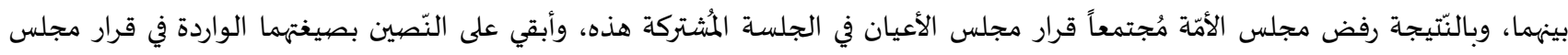

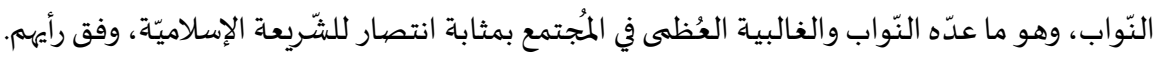

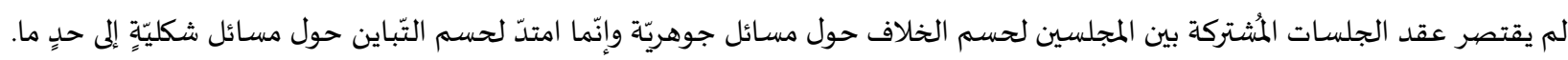

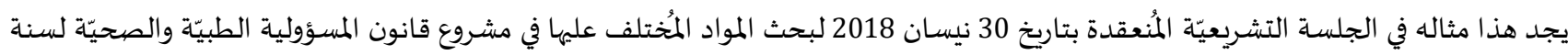

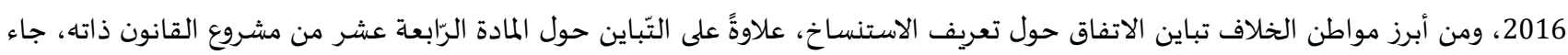

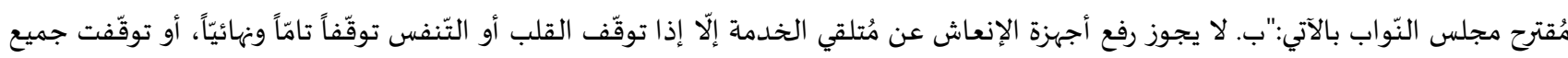

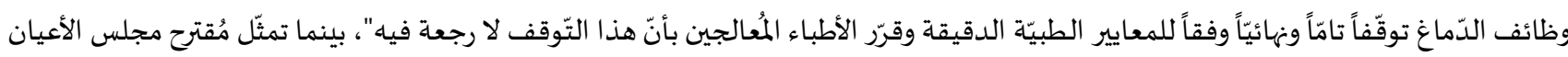

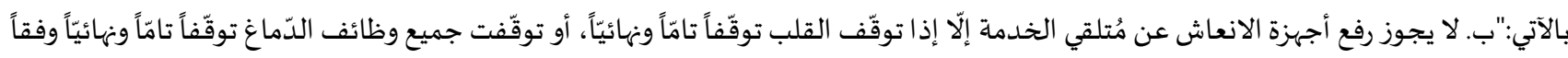

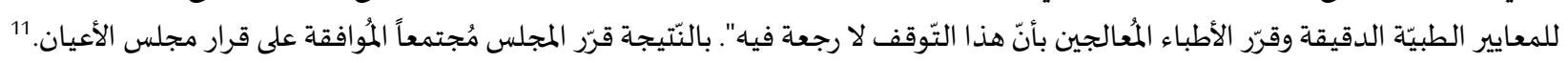

المطلب الثاني: نطاق الصّّلاحية التشريعيّة المنفردة للسّلطة التنفيذيّة

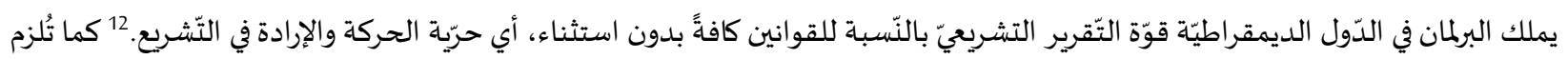

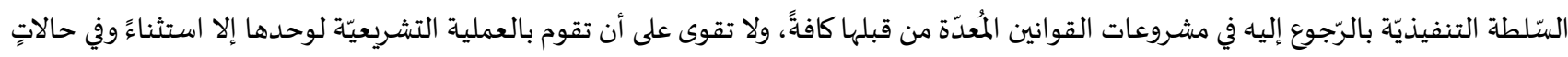

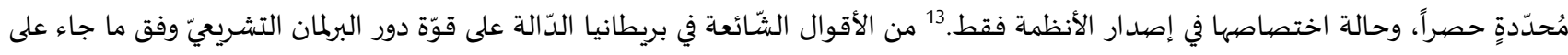

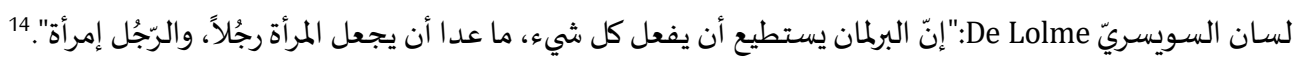

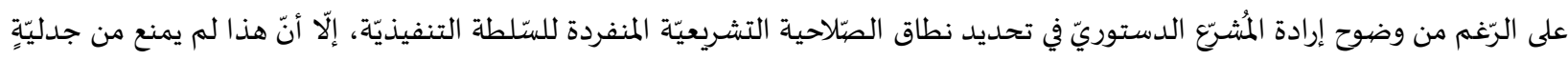

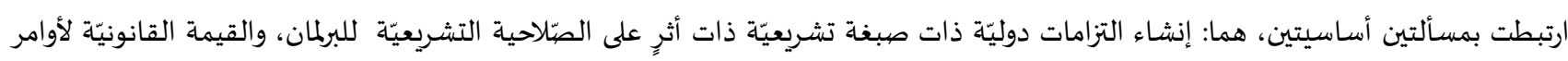

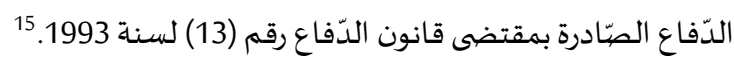

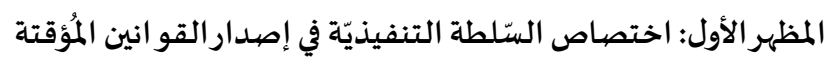

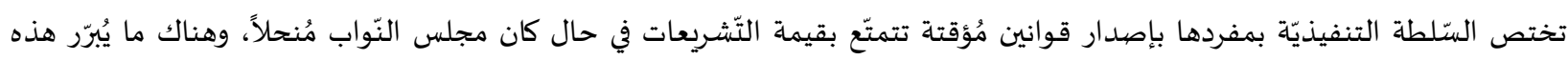

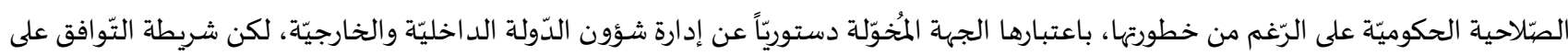

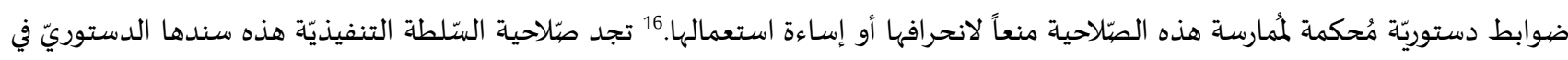

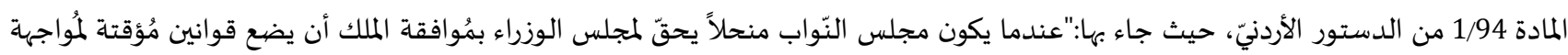

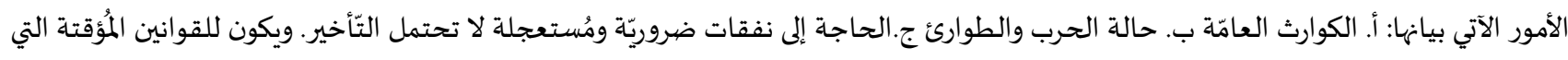

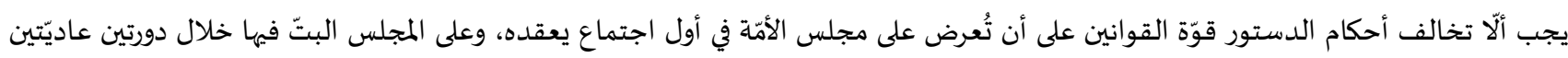

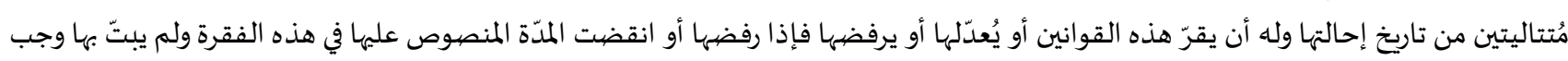

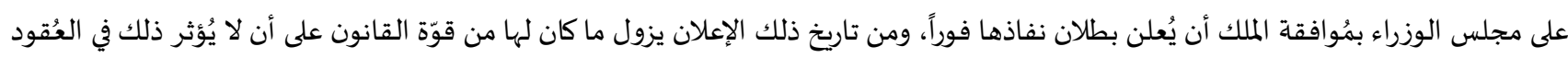
والحقوق المُكتسبة".

منح الدستور الأردنيّ السيّلطة التنفيذيّة صلاحية إصدار القوانين المُؤقتة، 17والتي من خلالها يستطيع مجلس الوزراء بمُوافقة الملك سنّ القوانين

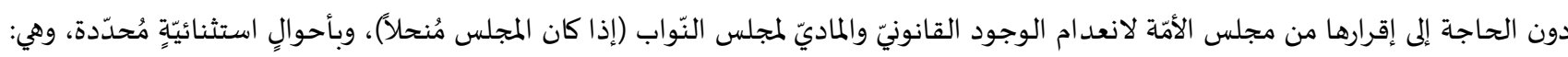

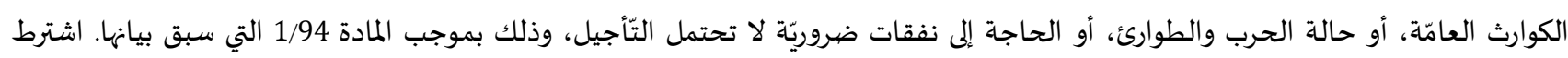

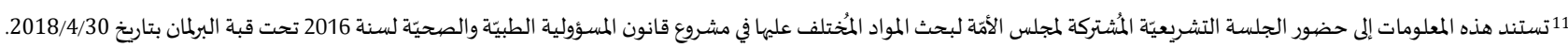

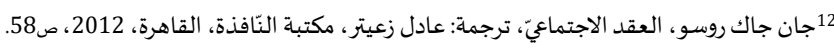

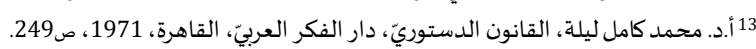

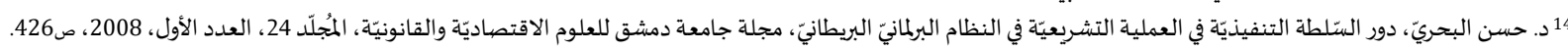

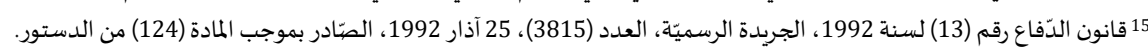
${ }^{16}$ Brian Z,Tamanaha., On the Rule of Law: History, Politics, Theory, Cambridge University Press, 2004, p.52.

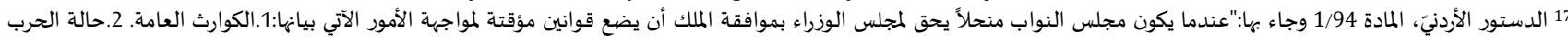
والطوارئ. 3. الحاجة إلى نفقات ضرورية ومُستعجلة لا لادة تحتمل التأجيل...". 
الدستور عرض هذه القوانين المُؤقتة على مجلس الأمَّة فور انعقاده، وأوجب على المجلس البتّ فهيها خلال دورتين عاديّتين مُتَاليتين من تاريخ إحالها،

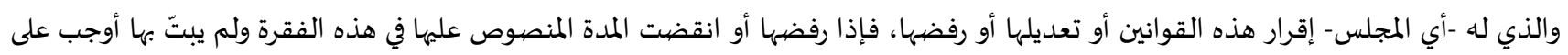

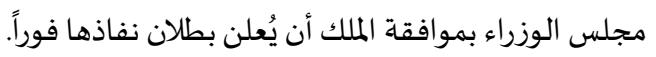

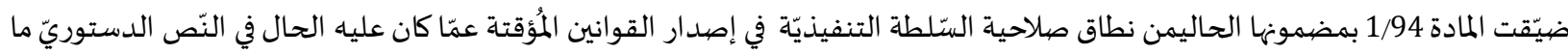

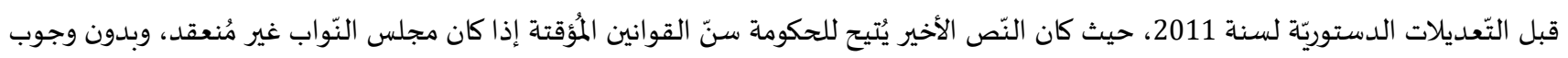
النّظر به من قِبل مجلس الأمَّة خلال فترة زمنيّةٍ مُحدّدة.

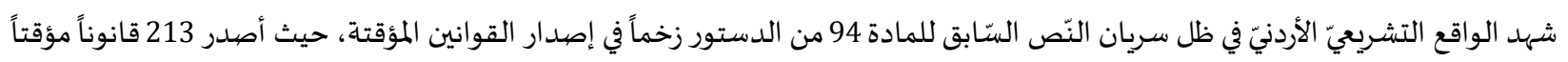

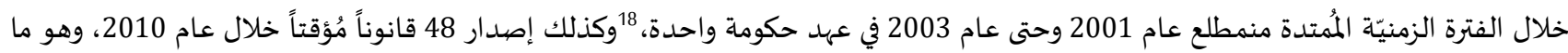

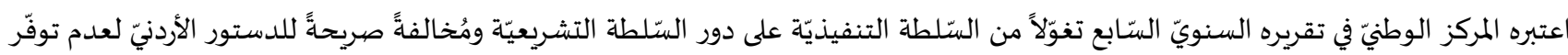

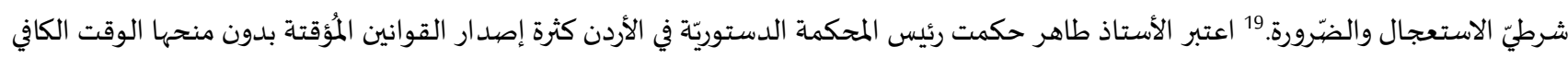

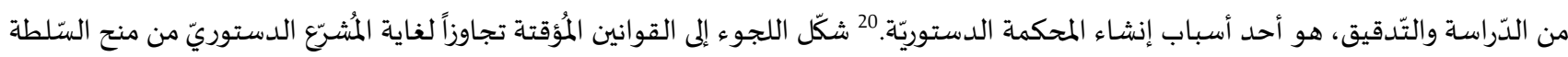

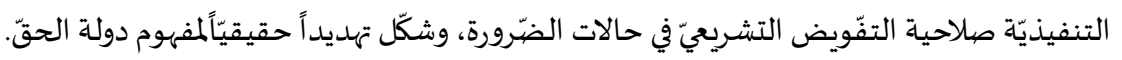

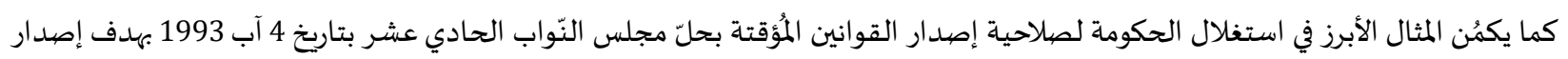

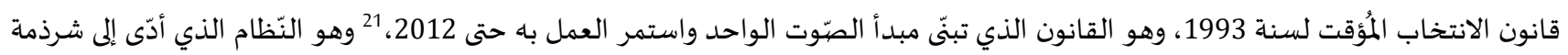

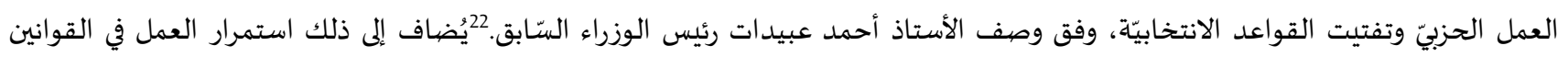

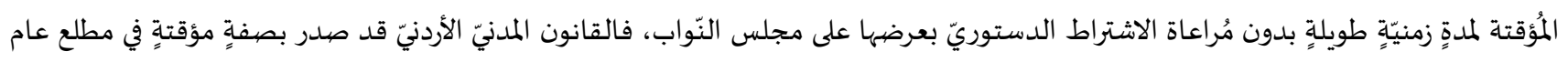

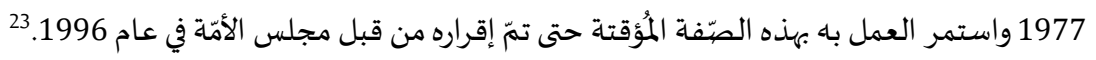

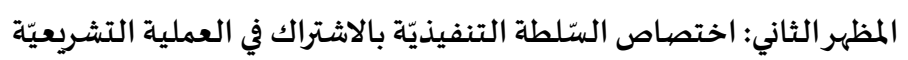

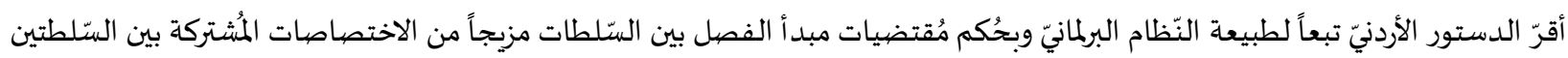

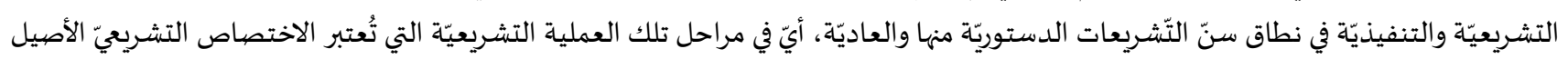

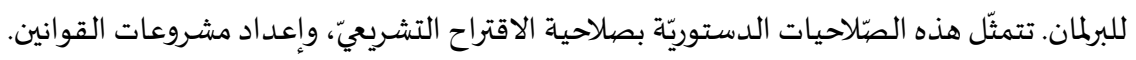

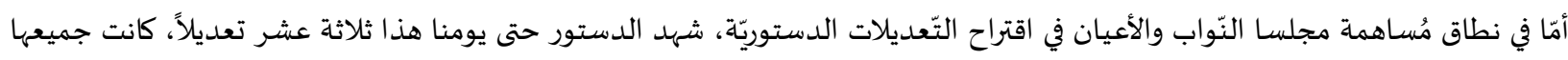

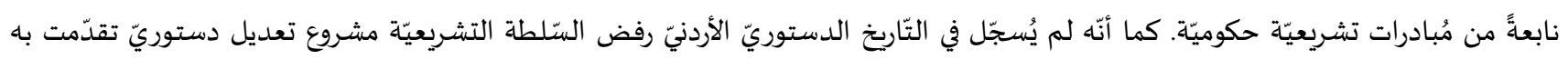

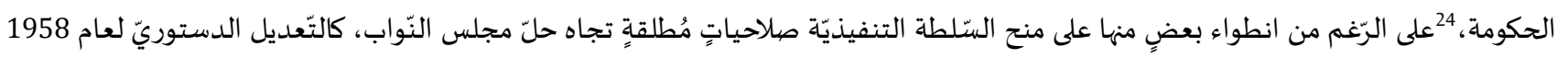

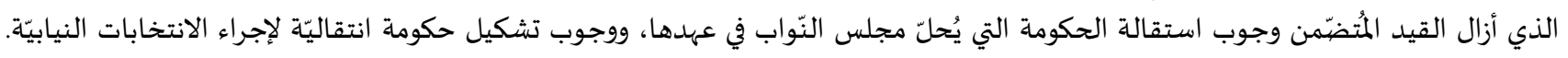

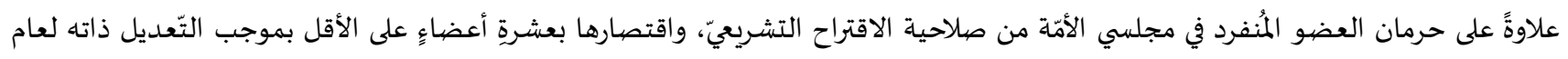

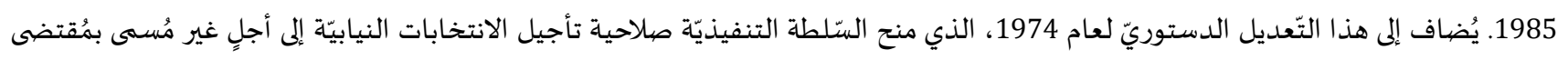

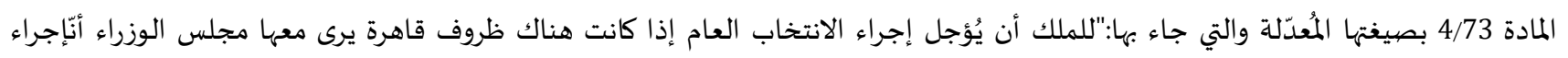

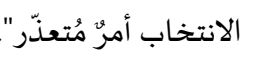

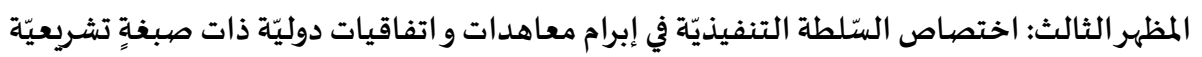

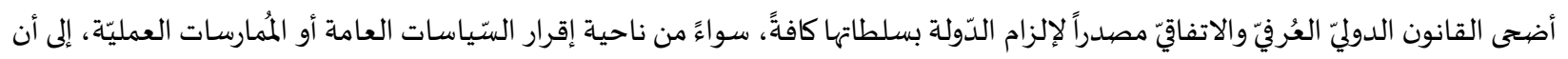

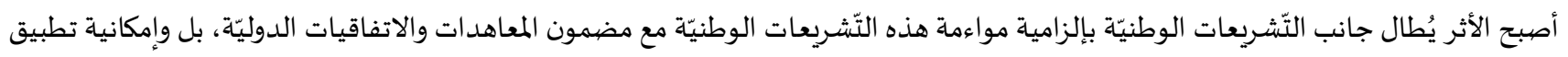

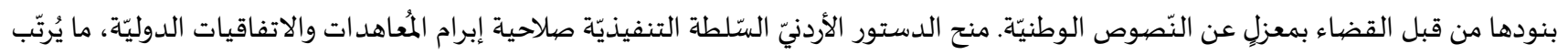
هذا التزاماتٍ تشريعيّةٍ على عاتق المجلس التشريعيّ وتقيّد صلاحيته التشريعيّة بمُوجبها.

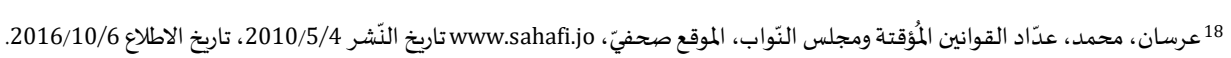

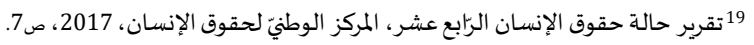

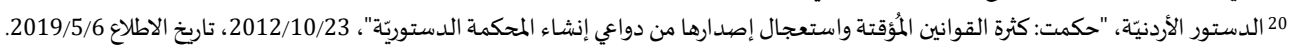

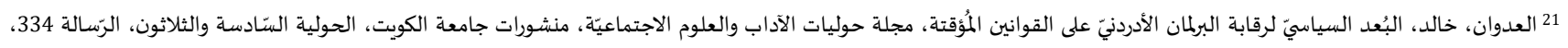
2016، صوب9.

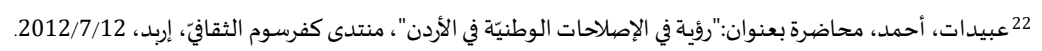

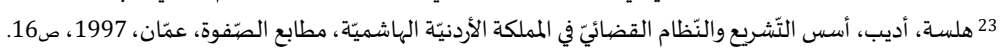

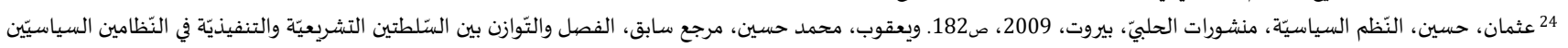
الأردنيّ واللبنانيّ، ص190، حسن. 
ارتبط الأردن بالعديد من المواثيق الدوليّة، التي تتضمّن أحكاماً ذات صبغةٍٍ تشريعيّةٍ وخصهوصاً المُتعلقة منها بحقوق الإنسان، ومثالها: العهدين

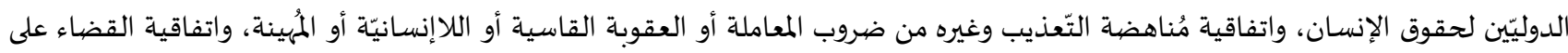

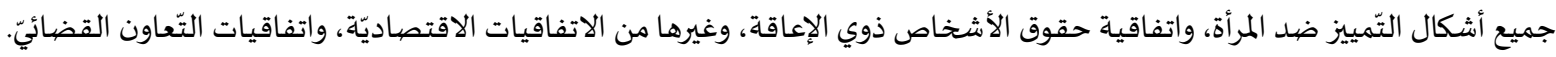

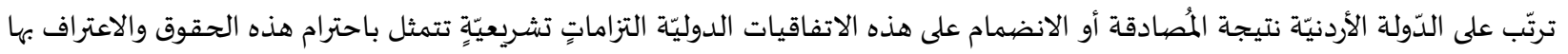

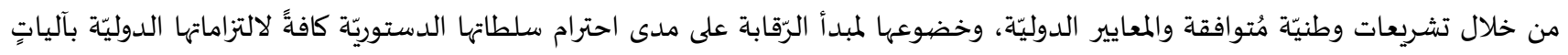

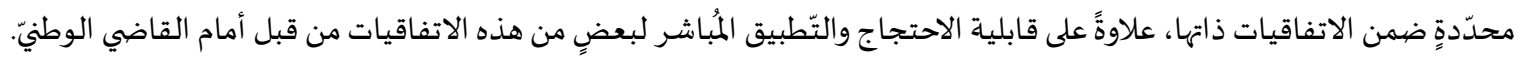

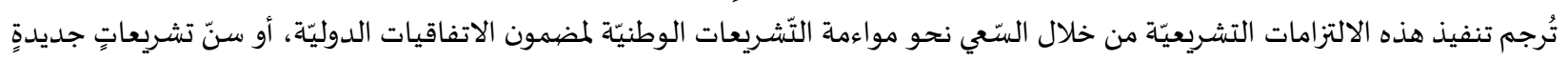

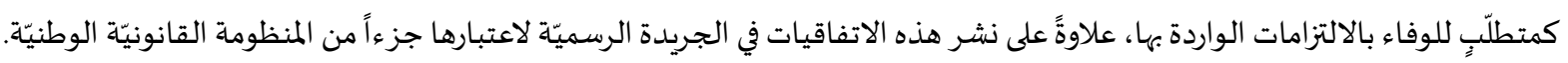

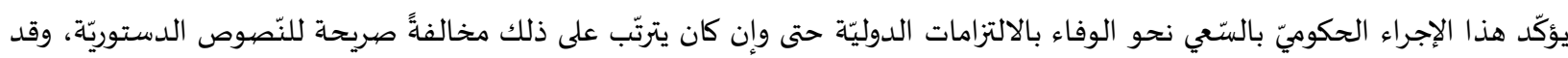

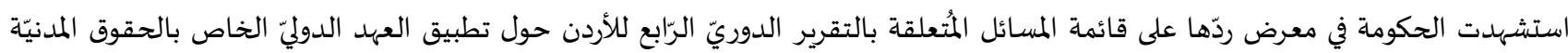

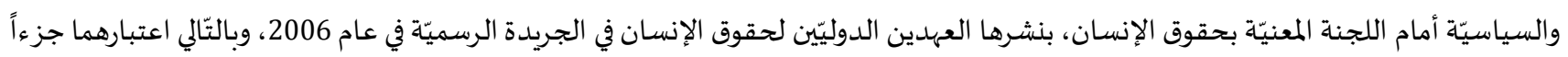

لا يتجزأ من التّشريع وسموّهما على القوانين الوطنيّة. 25

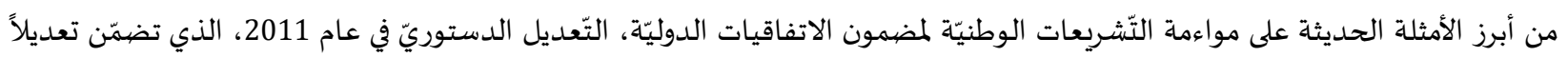

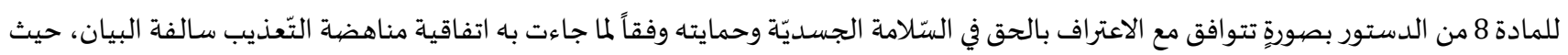

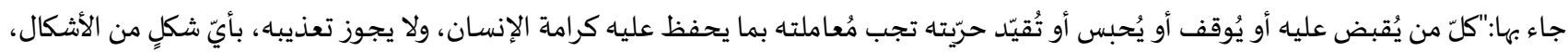
أو إيذاؤه بدنيّاً أو معنويَّاً..."

\section{المبحث الثاني: أوامر الدّفاع من منظوردستوريّ إنداء}

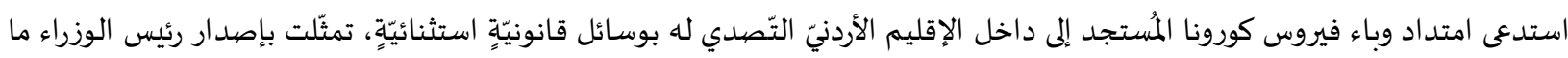

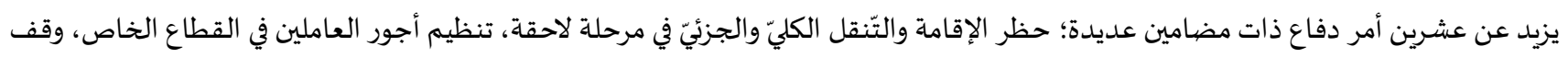

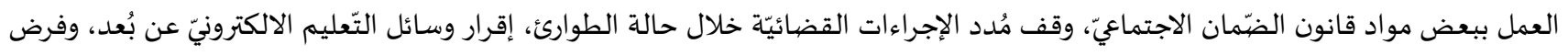
صور الحماية الجزائيّة للحقّ في الخصوصية.

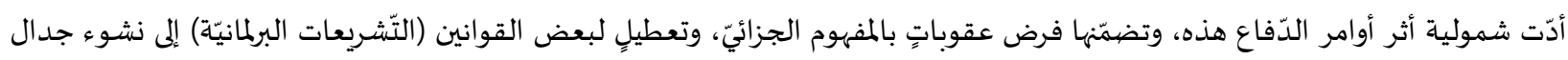
قانونيّ حول التكييف القانونيّ لأوامر الدّفاع، ومكانتها في النّظام القانونيّ الوطنيّ.

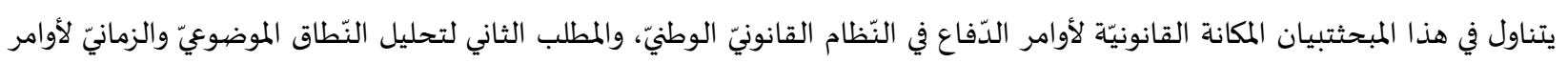
الدّفاع.

المطلب الأول: المكانة القانونيّة لأوامر الدّفاع في النّظام القانونيّ الوطنيّ

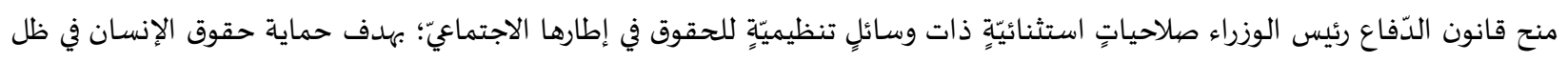
ظروف مؤقتة طارئة وصهولاً إلى العودة للوضيع القانونيّ الطبيعيّ. 26

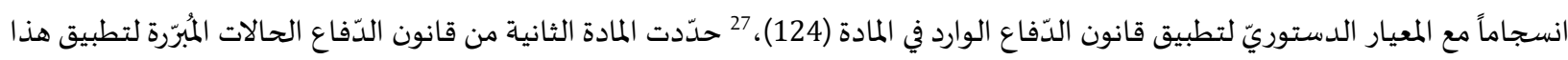

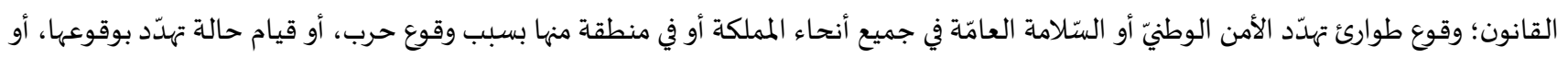

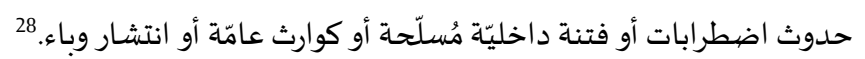

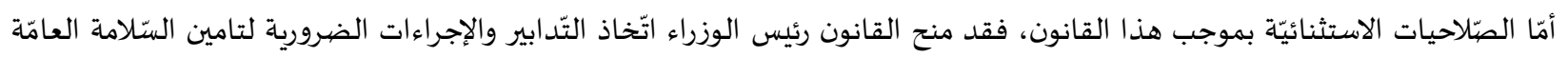
والدّفاع عن المملكة بدون التّقيد بأحكام القوانين العاديّة المعمول بها، بما في ذلك وضيع قيود على حرّّة الاشخاص في الاجتماع والانتقال والإقامة،

${ }^{25}$ Replies of the Government of Jordan to the list of issues to be taken up in Connection with the Consideration of the Fourth Periodic Report of Jordan, Human Rights committee. Hundredth session, Geneva, 11-29- Oc. 2010. Published in www.arab.human rights.org, Date of Entrance 16Oc.2017.

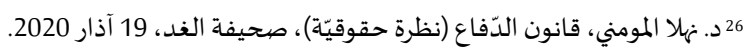

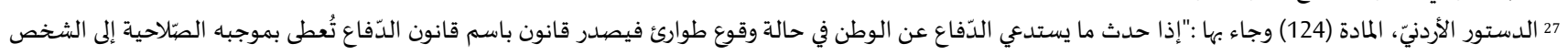

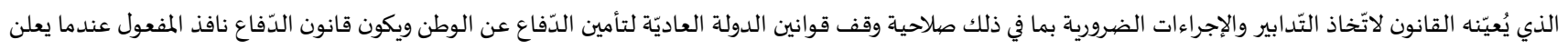

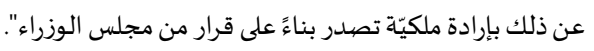

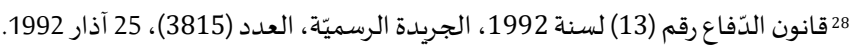




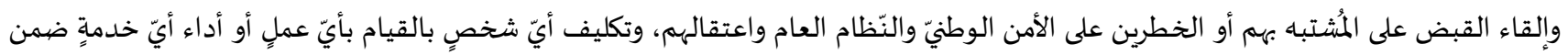

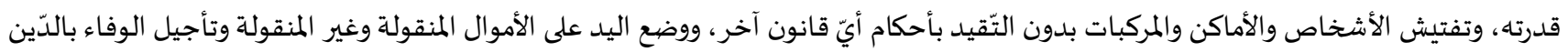

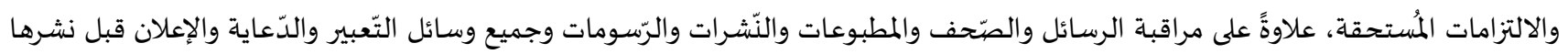
وضبطها ومصادرتها وتعطيلها وإغلاق أماكن إعدادها الماتها. 29

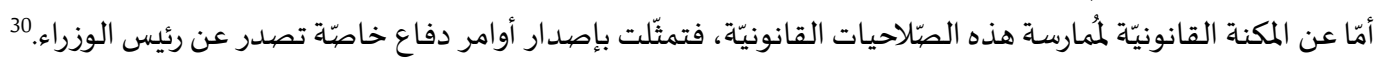

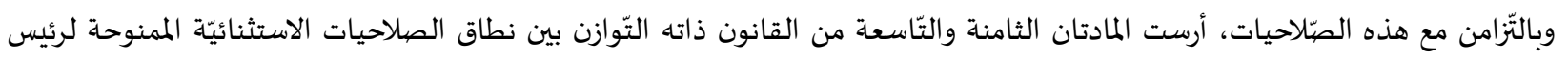

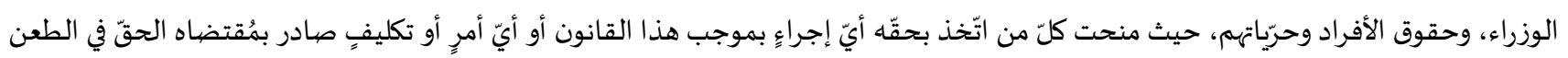

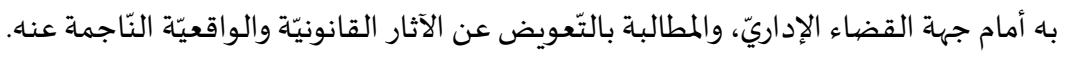

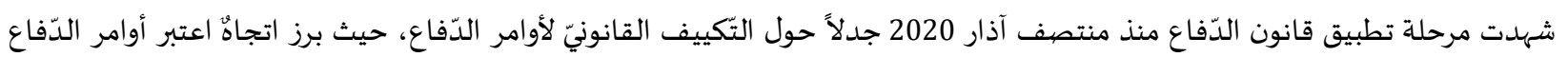

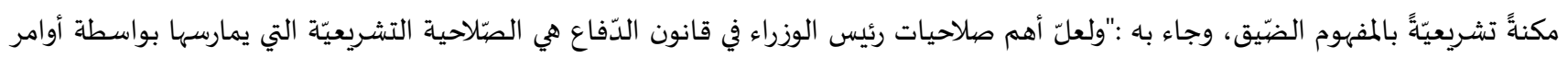

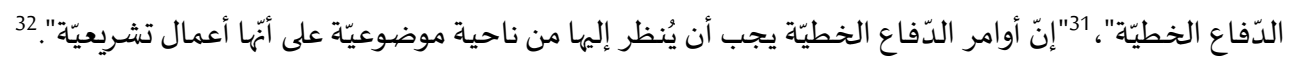

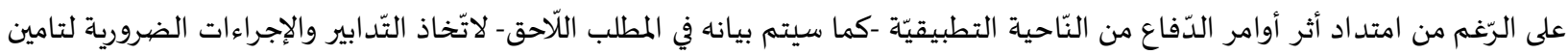

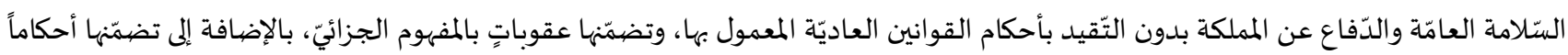

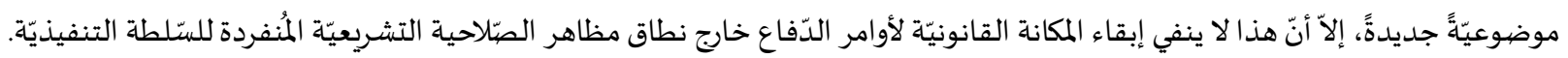

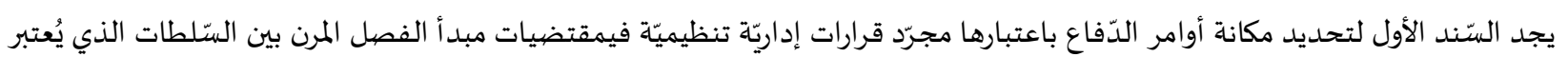

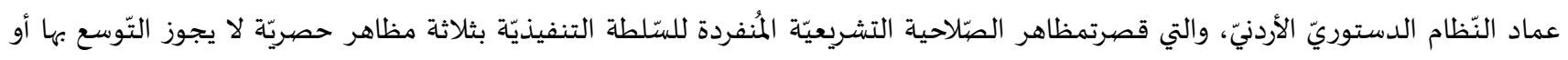

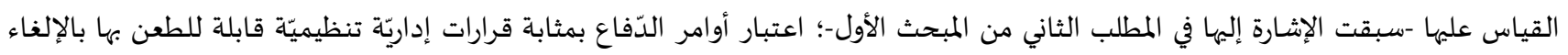
والتّعويض أمام جهة القضاء الإداريّ.

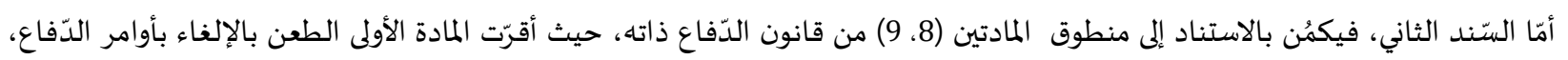

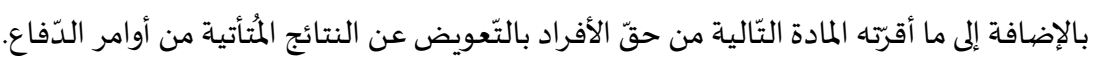

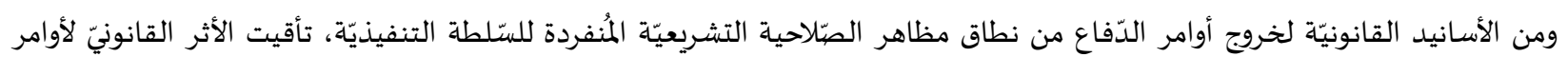

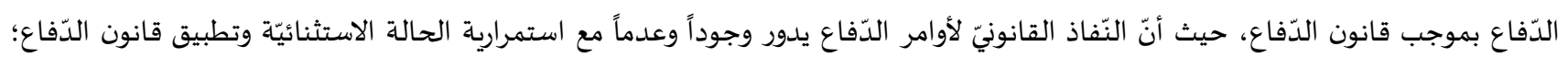

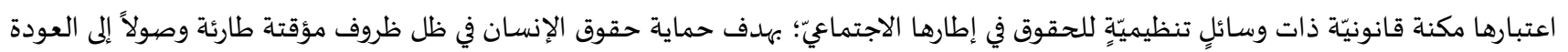

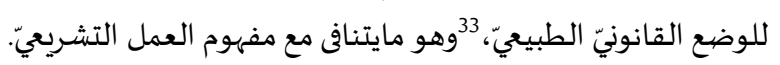

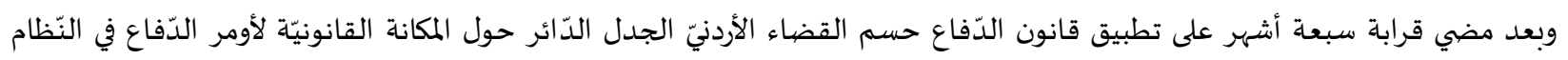

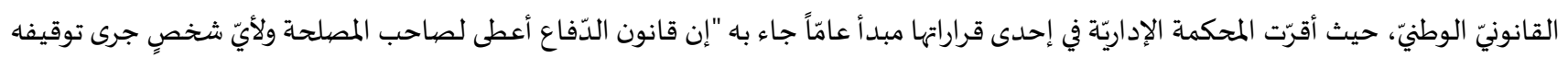

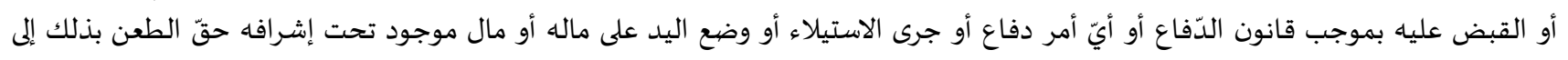

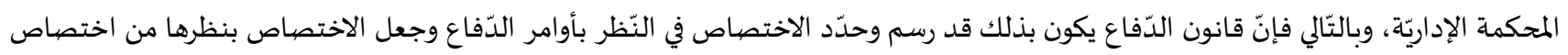

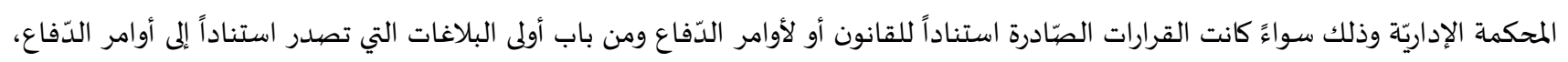

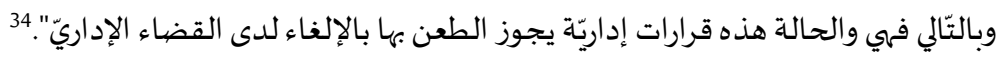

المطلب الثاني: النّطاق الموضهوعيّ والزمانيّ لأوامر الدّفاع

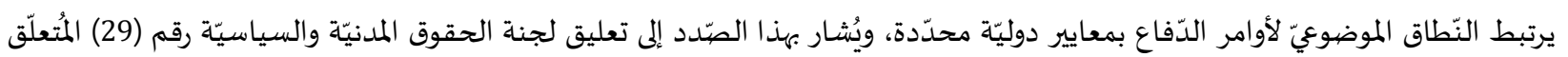

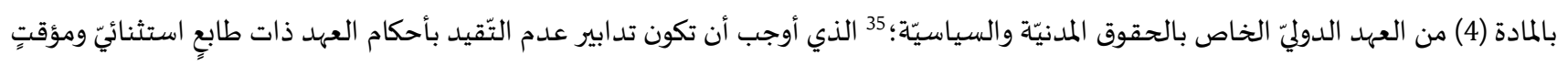
ووفقاً للشّروط التّالية:

29 قانون الدّفاع رقم (13) لسنة 1992، المادتين (13، (3) لسنة

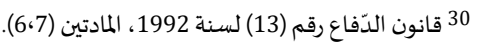

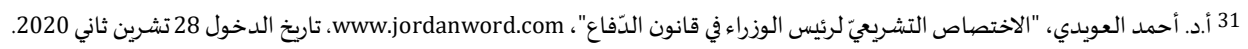

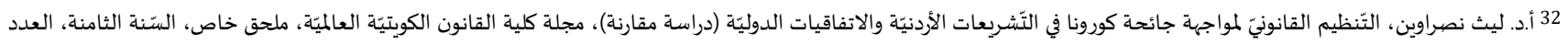

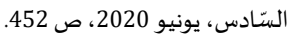

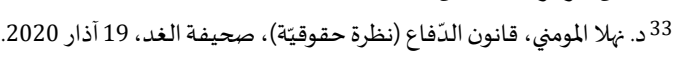

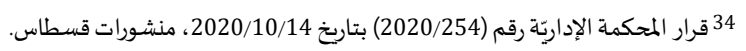
${ }^{35}$ General Comment No.29: States of Emergency (Article 4), CCPR/C/21/Rev.1/Add.11, 31 Aug 2001. 
أن تتّخذ مثل هذه التّدابير في أضيق الحدود التي تتطلها مقتضيات الوضع. وفقاً لما تنص عليه الفقرة (1) من المادة (4)؛ ويُلزم هذا الشّرط

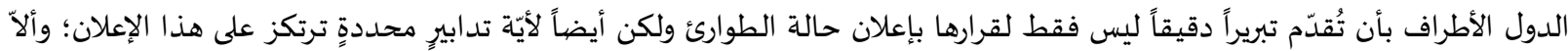

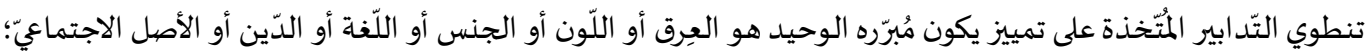
أن يكون الوضع بمثابة حالة طوارئ عامة تهدّد حياة الأمّة وأن تكون الدّولة الطرف قد أعلنت رسميّاً حالة الطوارئ؛ الحفاظ على مبدأيّ المشروعية وسيادة القانون، حيث يتعيّن على الدّول، عند إعلانها حالة طوارئ أن تتصرّف في حدود أحكام قانونها

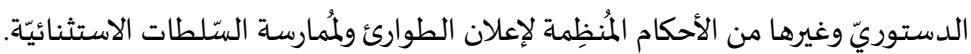

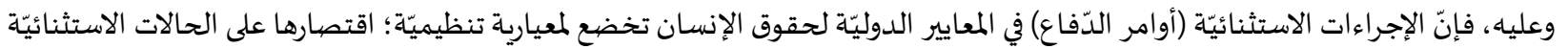

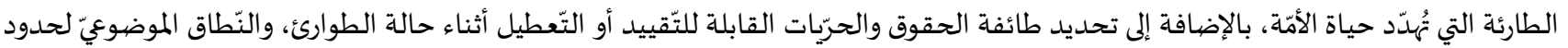

تقييد الحقوق وتعطيلها. أمّا على صعيد المنظومة القانونيّة الوطنيّة، فقد خلا الدستور الأردنيّ من تحديد الضّّوابط الدستوريّة للنّطاق الموضبوعيّ لأوامر الدّفاع بموجب

وفي ضوء هذا القصور الدستوريّ، أسّست الإرادة الملكيّة لتطبيق قانون الدّفاع بوادر أعرافٍ دستوريّةٍ مُكمّلةٍ لسد النّقص الدستوريّ حيال

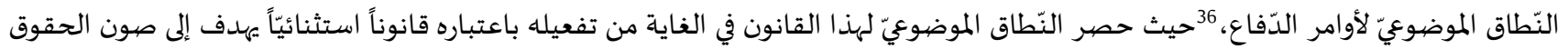

والحرّيات العامّة في ظرف استثنائيّ، وبالتّالي خروج القرارات غير الرّامية إلى تذليل العقبات التي تظهر خلال مواجهاة هذه الآفة عن نطاق المشروعية.

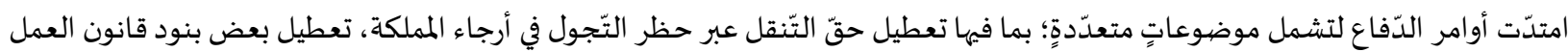

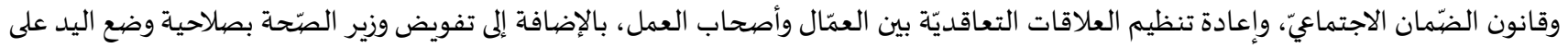

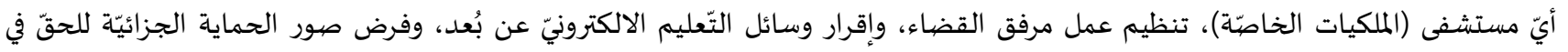
الخصوصية.

من خلال استعراض أوامر الدّفاع هذه وتحليلها في ضوء النّطاق الموضيوعيّ لفلسفة حالة الدّفاع، ومدى مراعاتها لاشتراط ضروريّة وتناسبيّة

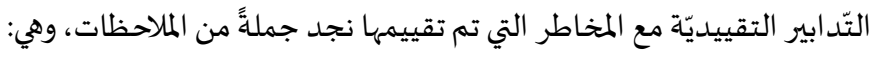

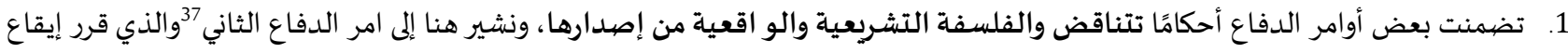

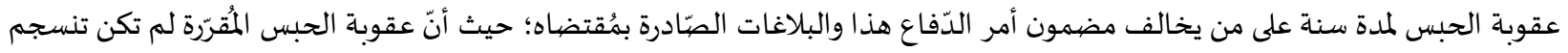
مع سياسة الحكومة ذاتها والمجلس القضائيّ في مُواجهة انتشار جائحة كورونا من خلال اتخاذ جملة من القرارات قضت بإخلاء سبيل الآلاف من فئن

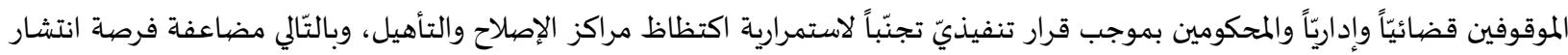

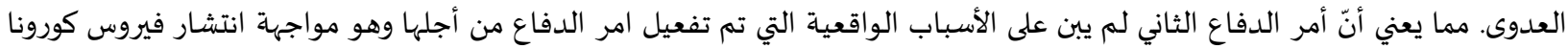
المستجدد.

2. أبرزت بعض أوامر الدفاع غياب التناسب ما بين الفعل المرتكب والإثم الجنائي، وبدا ذلك جليًا من خلال أمر الدفاع الثاني الذي فرض عقوبة

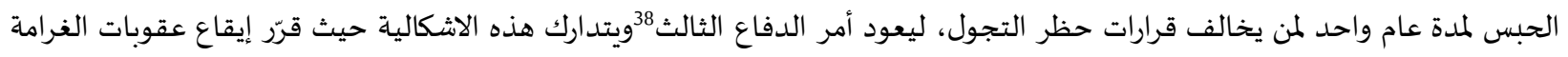

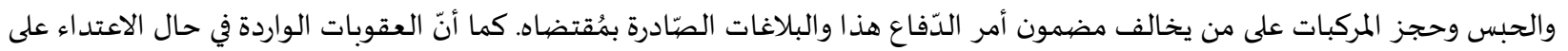

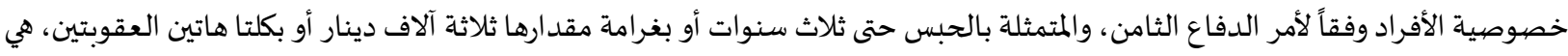
عقوبات مغلّظة تتجاوز جسامة الفعل المُرتكب.

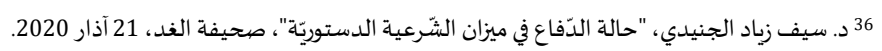

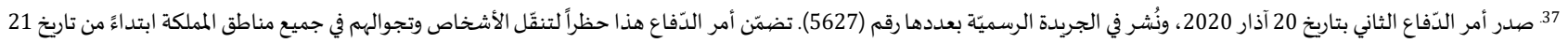

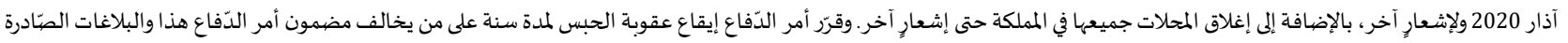

بمُقتضضاه.

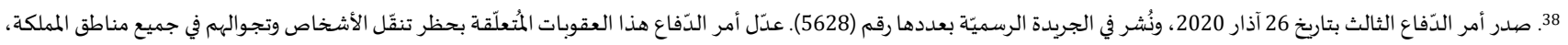

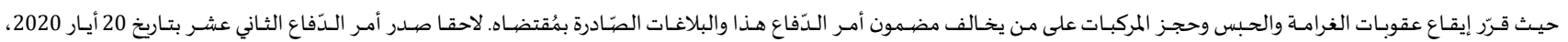

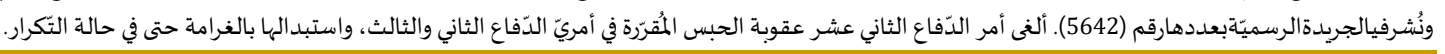


3. أبرزت بعض أوامر الدفاع غياب مبدأ التفريد العقابي وتكريس مبدأ التدرج في العقوبات وصولاً إلى تحقيق الردع العام والخاص؛ حيث فرضت

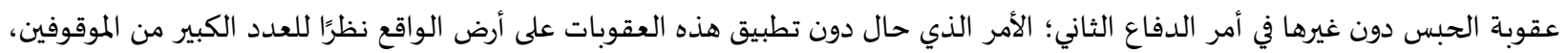

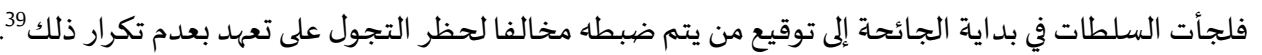

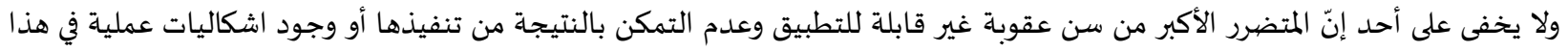

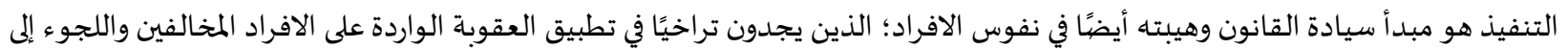

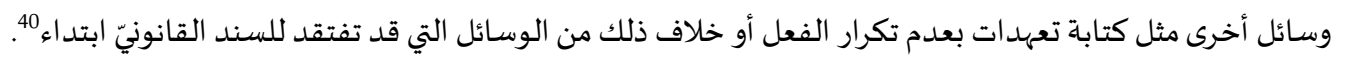

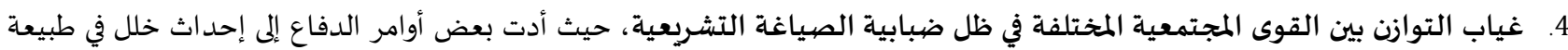

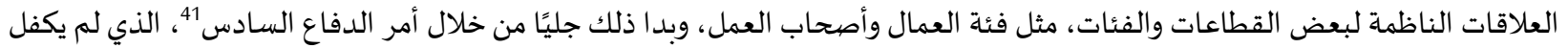

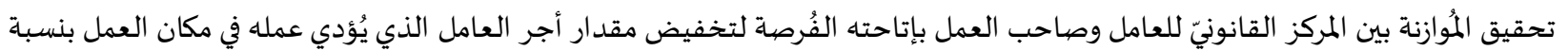

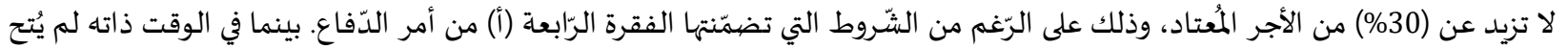

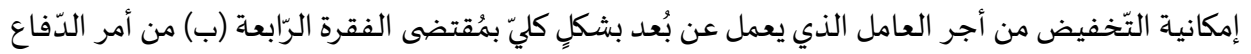

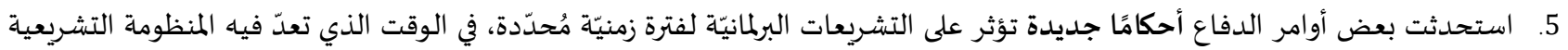

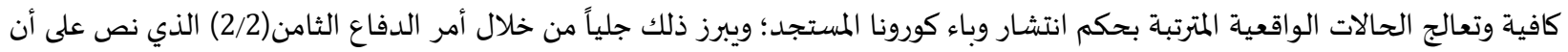

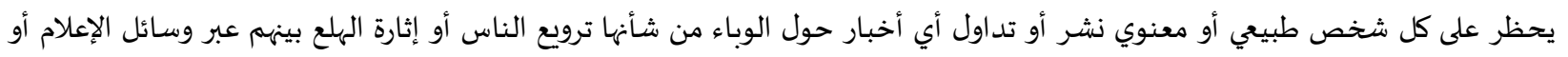

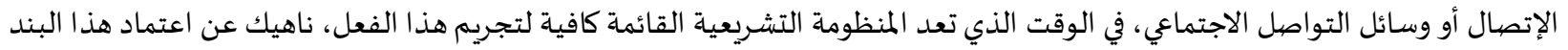
على عبارات عامة فضفاضة تؤدي إلى اضافة قيود اضافية على حرية التعبير وحرية الصحافة والإعلام وبالنتيجة اتساع نطاق الهاق الملاحقة الجزائية للأفراد دون وجود معيار قانوني وصورة واضحة للركن المادي المشكل لهذه الجريمة.

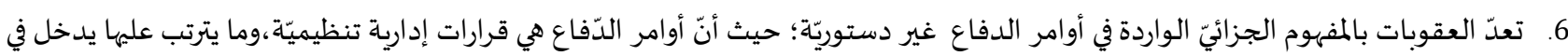
إطار إجراءات الضبط الإداري.

الخاتمةة:

تناولت هذه الدراسـة بالبحث والتحليل التكييف القانونيّ لأوامر الدفاع الصيّادرة استنادًا إلى قانون الدفاع، والذي تمّ تفعيله لأول مرّةٍ منذ

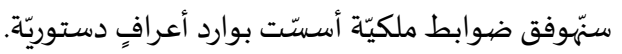

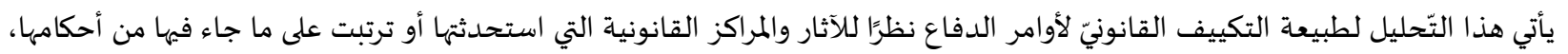
وفي إطار ما فرضتاه من عقوبات جزائية ابتداءً بالحبس وانتهاءً بفرض الغرامات الجزائية؛ وما نتج عنه في العديد من الحالات جدليّة أثر أوامر الدفاع على الصيّلاحية التشربعيّة. وقد انتهجت الدّراسـة في سبيل ذلك إلى تحليل جدلية إزدواجية صلاحية التشريع في الأردن، ومظاهر الصّّلاحية التشريعيّة المُنفردة للسّّلطة

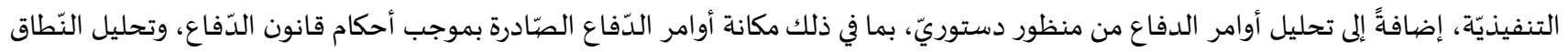
الموضيوعيّ والزمانيّ لهذه الأوامر. وخلصت الدراسة إلى نتيجةٍ قانونيّةٍ تتلخّص بالاستحالة القانونيّة لوجود أثرٍٍ لقانون الدّفاع على الصّّلاحية التشريعيّة، حيث أنّ أوامر الدّفاع

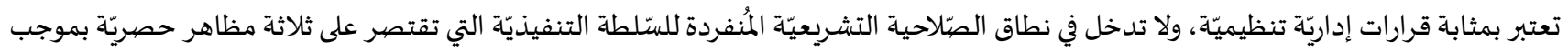

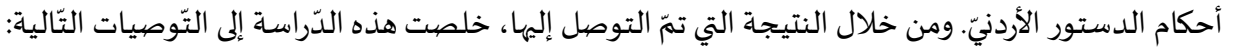

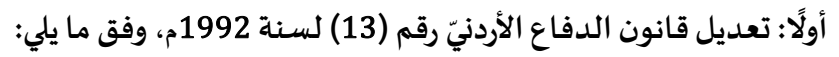

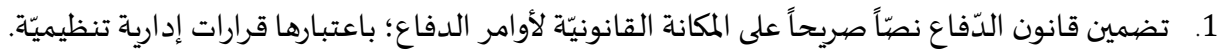

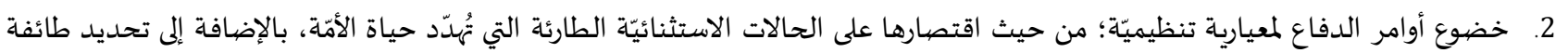
الحقوق والحرّيات القابلة للتّقييد أو التّعطيل أثناء حالة الطوارئ، والنّطاق الموضيّوعيّ لحدود تقييد الحقوق وتعطيلها.

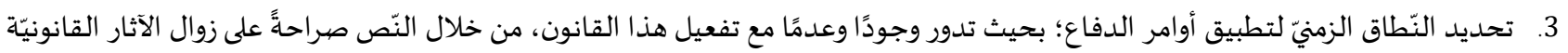

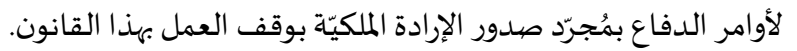

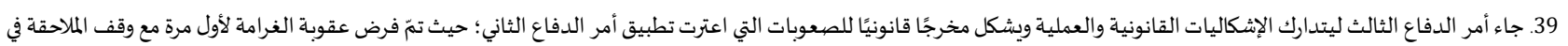

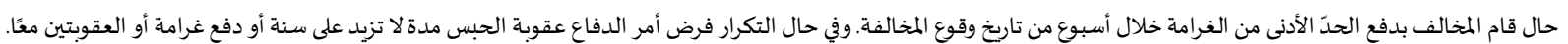

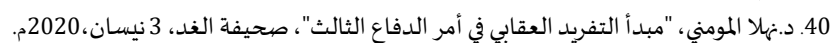

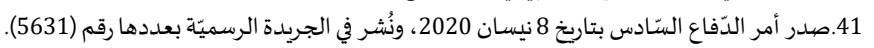


ثانيًا: مراجعة أوامر الدّفاع الصيّادرة استناداً إلى قانون الدفاع بما يضمن انسجامها والغاية المعيارية والنطاق الموضوعي لإصدارها، والمتمثلة في مواجهة الظرف الطارئ.

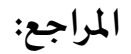

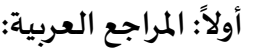

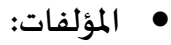

1. حسين، عثمان (2009). النّظم السياسيّة. بيروت: منشورات الحلبيّ.

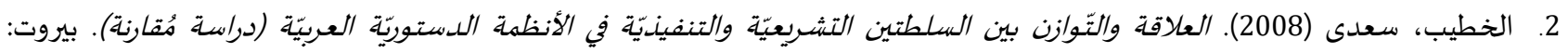

$$
\text { 3. دوفرجياه، موريس (1992). المؤسسات السبيّة الحقوقيّة. }
$$

4. روسو، جان جاك (2012). العقد الاجتماعيّ. ترجمة: زعيتر ، عادل. القاهرة: مكتبة النّافذة.

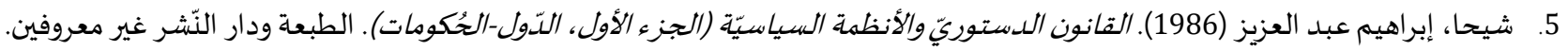

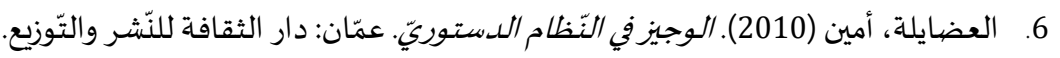

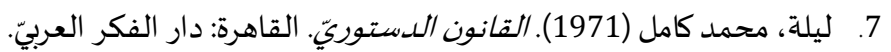

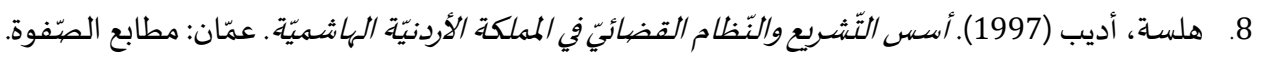

9 9. يعقوب، محمد حسين (2004). الفصيل والتّوازن بين السّلطتين التشريعيّة والتنفينيّة في النظامين السياسيّين الأردنيّ واللبنانيّ. الطبعة الأولى.

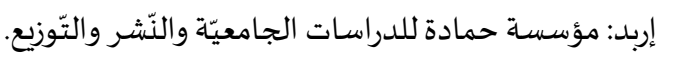

الأبححاث المُحُكّمة:

1. البحريّ، حسن (2008). دور السّلطة التنفيذيّة في العملية التشريعيّة في النظام البرلمانيّ البريطانيّ. مجلة جامعة دمشق للعلوم الاقتصاديّة

والقانونيّة: 24 (1).

2. أبو رمّان، حسين (2016). الغرفة التشريعيّة الثّانية: التّحربة الأردنيّة في السّياق الدوليّ. عمّان: منشورات مركز القدس للدّراسات السياسيّة

$$
\text { ومرصد البرلمان الأردنيّ. }
$$

3. زريقات، فايز (2009). محجلس الأعيان ودوره في النظام السياسيّ الأردنيّ (دراسة تشريعيّة مقارنة). جامعة آل البيت، المفرق: مجلة المنارة. 15(3).

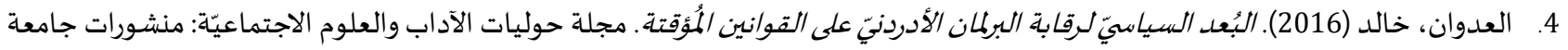
الكويت. الحولية السّادسة والثلاثون، الرّسالة 334.

$$
\text { • }
$$

1. تقرير حالة حقوق الإنسان الرّابع عشر (2017)، المركز الوطنيّ لحقوق الإنسـان.

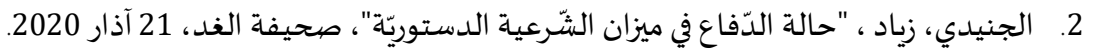

3. الدستور الأردنيّة.

4. عبيد ات، أحمد، محاضرة بعنوان:"رؤية في الإصلاحات الوطنيّة في الأردن"، منتدى كفرسوم الثقافيّ، إربد، 2012/7/12.

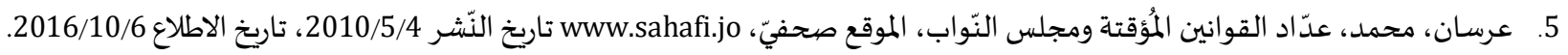
6. العويدي، أحمد، "الاختصاص التشريعيّ لرئيس الوزراء في قانون الدّفاع"، www.jordanword.com، تاريخ الدخول 28 تشرين ثاني 2020.

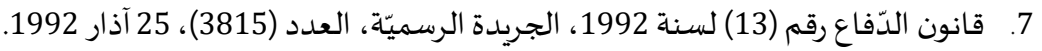

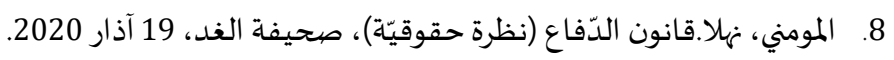

$$
\begin{aligned}
& \text { 9. المومني، نهلا. "مبدا التفريد العقابي في امر الدفاع الثالث، صحيفة الغد، } 3 \text { نيسان، 2020م. }
\end{aligned}
$$

ثانياً: المراجع الأجنبيّة:

1. Tamanaha, Brian (2004). On the Rule of Law: History, Politics, Theory, Cambridge University Press.

2. Replies of the Government of Jordan to the list of issues to be taken up in Connection with the Consideration of the Fourth Periodic Report of Jordan, Human Rights committee. Hundredth session, Geneva, 11-29- Oc. 2010. Published in www.arab.human rights.org, Date of Entrance 16-0c.2017

3. General Comment No.29: States of Emergency (Article 4), CCPR/C/21/Rev.1/Add.11, 31 


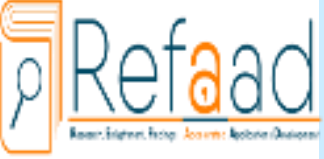

www.refaad.com
المجلة الدولية للدراسـات القانونية والفقهية المقارنة

International Journal of Legal and Comparative Jurisprudence Studies (LCJS)

Journal Homepage: https://www.refaad.com/views/LCJS/Home.aspx

ISSN: 2708-6607(Online) 2708-6593(Print)

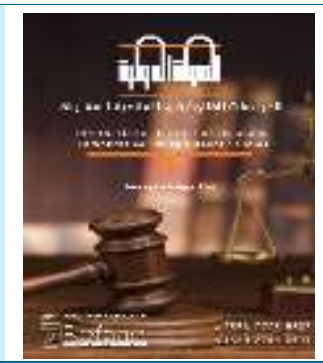

\title{
The impact of defense orders on legislative authority
}

\section{Saif Ziad AL Junidi}

PHD in Constitutional and Administrative Law, Head of the National Legislation Unit, the National Center for Human Rights/ Jordan aljunidisaif@hotmail.com

\section{Nahla Abdelkader AL Momani}

$\mathrm{PhD}$ in Public International Law, Facilitator of the Protection Commission, National Center for Human Rights/ Jordan

nahla400086@yahoo.com

\author{
Received: 14/2/2021 Revised: 12/4/2021 Accepted: 22/4/2021 DOI: https://doi.org/10.31559/LCJS2021.2.1.3
}

\begin{abstract}
This study with its hypothetical title had discussed the realistic argument of the impact caused by the defense orders on the legislative authority. The study methodology had focused on analyzing the position $\mathrm{n}$ of the defense orders issued by the defense law no. (13) Year 1992. This problems effected the principle of separation of powers since defense orders include provisions regulate the rights,\& provide criminal penalties.

The hypothetical title of the study came as a result of a legal consequence just boils down to legal impossibility to find existence of legal effect of defense orders on the legislative authority, the study finds that the defense orders are considered as administrative decision, and did not fall within the scope of legislative authority of the executive power which only extends on three aspects under the constitution, also the study had discussed the realistic and legal reasons and the problems of implementation and overrun the legislative authority of the parliament, making proposal and amendment that incorporate the requirements of the principle of separation of powers in exercising the legislative duties.
\end{abstract}

Keywords: Defense Law; Defense orders; Constitutional Monarchy; constitutional legality; the principle of separation of powers.

\section{References:}

1. Al'daylh, Amyn (2010). Alwjyz Fy Alnzam Aldstwry. 'man: Dar Althqafh Llnshr Waltwzy'.

2. Al'dwan, Khald (2016). Albu'd Alsyasy Lrqabh Albrlman Aladrdny 'la Alqwanyn Almu'qth. Mjlt Hwlyat Aladab Wal'Iwm Alajtma'yh: Mnshwrat Jam't Alkwyt. Alhwlyh Alsadsh Walthlathwn, Alrsalh 334.

3. Albhry, Hsn (2008). Dwr Alslth Altnfydyh Fy Al'mlyh Altshry'yh Fy Alnzam Albrlmany Albrytany. Mjlt Jam't Dmshq Ll'lwm Alaqtsadyh Walqanwnyh: 24(1).

4. Dwfrjyh, Mwrys (1992). Alm'ssat Alsyasyh Walqanwn Aldstwry. Byrwt: Alm'ssh Aljam'yh Lldrasat Walnshr Waltwzy'.

5. Hlsh, Adyb (1997). Ass Altshry' Walnzam Alqda'y Fy Almmlkh Alardnyh Alhashmyh. 'man: Mtab' Alsfwh.

6. Hsyn, 'thman (2009). Alnzm Alsyasyh. Byrwt: Mnshwrat Alhlby.

7. Alkhtyb, S'da (2008). Al'laqh Waltwazn Byn Alslttyn Altshry'yh Waltnfydyh Fy Alanzmh Aldstwryh Al'rbyh (Drash Muqarnh). Byrwt: Mnshwrat Alhlby Alhqwqyh.

8. Lylh, Mhmd Kaml (1971). Alqanwn Aldstwry. Alqahrh: Dar Alfkr Al'rby. 
9. Abw Rman, Hsyn (2016). Alghrfh Altshry'yh Althanyh: Altjrbh Alardnyh Fy Alsyaq Aldwly. 'man: Mnshwrat Mrkz Alqds Lldrasat Alsyasyh Wmrsd Albrlman Alardny.

10. Rwsw, Jan Jak (2012). Al'qd Alajtma'y. Trjmt: Z'ytr, 'adl. Alqahrh: Mktbt Alnafdh.

11. Shyha, Ebrahym 'bd Al'zyz (1986). Alqanwn Aldstwry Walanzmh Alsyasyh (Aljz' Alawl, Aldwl-Alhukwmat). Altb'h Wdar Alnshr Ghyr M'rwfyn.

12. Y'qwb, Mhmd Hsyn (2004). Alfsl Waltwazn Byn Alslttyn Altshry'yh Waltnfydyh Fy Alnzamyn Alsyasyyn Alardny Wallbnany. Altb'h Alawla. Erbd: M'sst Hmadh Lldrasat Aljam'yh Walnshr Waltwzy'.

13. Zryqat, Fayz (2009). Mjls Ala'yan Wdwrh Fy Alnzam Alsyasy Alardny (Drash Tshry'yh Mqarnh). Jam't Al Albyt, Almfrq: Mjlt Almnarh. 15(3). 